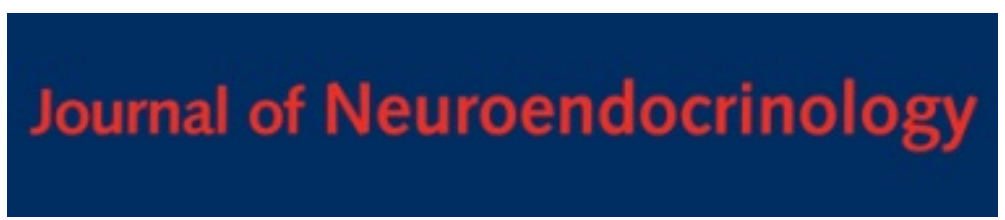

\title{
Sex- and sub region-dependent modulation of arcuate kisspeptin neurons by vasopressin and vasoactive intestinal peptide
}

\begin{tabular}{|r|l|}
\hline Journal: & Journal of Neuroendocrinology \\
\hline Manuscript ID & JNE-18-0113-OA.R1 \\
\hline Manuscript Type: & Original Article \\
\hline Author: & n/a \\
\hline Complete List of Authors: & $\begin{array}{l}\text { Schafer, Danielle; University of Otago, Centre for Neuroendocrinology } \\
\text { and Department of Physiology } \\
\text { Kane, Grace; University of Otago, Centre for Neuroendocrinology and } \\
\text { Department of Physiology } \\
\text { Colledge, William; University of Cambridge, Physiology, Development } \\
\text { and Neuroscience } \\
\text { Piet, Richard; Otago School of Medical Sciences, Physiology } \\
\text { Herbison, Allan; University of Otago, Centre for Neuroendocrinology and } \\
\text { Department of Physiology }\end{array}$ \\
\hline Keywords: & Kisspeptin, GnRH, Neurokinins, Vasopressin, calcium, sex differences \\
\hline &
\end{tabular}


14 Short title: Neuropeptide modulation of arcuate kisspeptin neurons

Correspondence to:

${ }^{1}$ Centre for Neuroendocrinology and Department of Physiology, School of Biomedical Sciences, University of Otago, Dunedin 9054, New Zealand, and ${ }^{2}$ Reproductive Physiology Group, Department of Physiology, Development and Neuroscience, University of Cambridge, Cambridge CB2 3EG, United Kingdom.

\section{vasopressin and vasoactive intestinal peptide}

Centre for Neuroendocrinology and Department of Physiology, Otago School of Medical Sciences, University of Otago, Dunedin, New Zealand 9054

$24 \quad$ Tel +643479 7312

25 Email: allan.herbison@otago.ac.nz

30 Key words: GCAMP, kisspeptin, neurokinin B, sex differences, vasoactive intestinal

31 peptide, vasopressin 


\section{Abstract}

34 A population of kisspeptin neurons located in the hypothalamic arcuate nucleus 35 (ARN) very likely represent the gonadotrophin-releasing hormone pulse generator 36 responsible for driving pulsatile luteinizing hormone secretion in mammals. As such, 37 it has become important to understand the neural inputs that modulate the activity 38 of ARN kisspeptin (ARN ${ }^{\mathrm{KISS}}$ ) neurons. Using a transgenic GCaMP6 mouse model 39 allowing the intracellular calcium levels $\left(\mathrm{i}\left[\mathrm{Ca}^{2+}\right]\right.$ ) of individual $\mathrm{ARN}^{\mathrm{KISS}}$ neurons to be 40 assessed simultaneously, we examined whether the circadian neuropeptides 41 vasoactive intestinal peptide (VIP) and arginine vasopressin (AVP) modulated the 42 activity of ARN ${ }^{\mathrm{KISS}}$ neurons directly. To validate this methodology, we initially 43 evaluated the effects of neurokinin $\mathrm{B}(\mathrm{NKB})$ on $\mathrm{i}\left[\mathrm{Ca}^{2+}\right]$ in kisspeptin neurons residing 44 within the rostral, middle and caudal ARN subregions of adult male and female mice. 45 All experiments were undertaken in the presence of tetrodotoxin and ionotropic 46 amino acid antagonists. NKB was found to evoke an abrupt increase in $\mathrm{i}\left[\mathrm{Ca}^{2+}\right]$ in $95-$ $47100 \%$ of kisspeptin neurons throughout the ARN of both sexes. In marked contrast, 48 both VIP and AVP were found to primarily activate kisspeptin neurons located in the 49 caudal ARN of female mice. Whereas 58 and 59\% of caudal ARN kisspeptin neurons 50 responded to AVP and VIP, respectively, in female mice, only $0-8 \%$ of kisspeptin 51 neurons located in other ARN subregions responded in females and $0-12 \%$ of cells in 52 any subregion in males $(\mathrm{p}<0.05)$. These observations demonstrate unexpected sex 53 differences and marked heterogeneity in functional neuropeptide receptor 54 expression amongst ARN ${ }^{\text {KISS }}$ neurons organized on a rostro-caudal basis. The 55 functional significance of this unexpected influence of VIP and AVP on ARN ${ }^{\text {KISS }}$ 56 neurons remains to be established. 


\section{Introduction}

58 The pulsatile release of luteinizing hormone (LH) is critical for fertility. Adult males

59 exhibit an LH pulse approximately every $3 \mathrm{~h}$ while females show variable LH pulse

60 rates ranging from a pulse every hour in the follicular phase to one every $3 \mathrm{~h}$ in the

61 luteal phase of the cycle (1). However, a variety of internal and external factors can

62 drive LH pulse frequency outside this normal range to suppress fertility. For example,

63 the high LH pulse frequency of females with polycystic ovary syndrome and slow

64 pulsatility observed in hypothalamic amenorrhea are often associated with infertility $65(2-4)$.

66 Studies examining a range of mammalian species over recent years have indicated

67 that kisspeptin neurons co-expressing neurokinin B and dynorphin (KNDy neurons)

68 located in the hypothalamic arcuate nucleus are responsible for generating the

69 pulsatile pattern of gonadotropin-releasing hormone $(\mathrm{GnRH})$ release that drives

70 pulsatile LH secretion $(1,5)$. As such, the arcuate nucleus KNDy or kisspeptin

71 (ARN ${ }^{\text {KISS}}$ ) neurons have become a focal point for investigators wanting to understand

72 how different physiological and pathophysiological factors influence LH pulse 73 frequency $(1,6,7)$.

74 Although the definition and role of circadian inputs to the preoptic population of 75 kisspeptin neurons has received much attention $(8,9)$, no information exists 76 regarding the potential circadian regulation of the ARN KISS neurons. Studies in

77 humans have identified sleep-wake variations in LH pulse frequency (10-12) raising 78 the possibility that some form of circadian input may also be directed at the ARN ${ }^{\text {KISS }}$ 79 neurons. To begin to investigate this possibility, we have examined whether ARN ${ }^{\text {KISS }}$ 80 neurons in the mouse express functional receptors for arginine vasopressin (AVP) 81 and vasoactive intestinal peptide (VIP), the two major neuropeptidergic outputs from 82 the suprachiasmatic nucleus (SCN). Studies in rats and mice have identified receptors 83 for both of these neuropeptides in the arcuate nucleus (13-15) and SCN neurons are 84 known to project to and modulate the activity of ARN neurons in the rat $(16,17)$.

85 However, we note that many neural populations expressing VIP and AVP are also 86 found outside the SCN and may conceivably have a role in regulating LH secretion. 
88 To examine the potential effects of AVP and VIP, we have established a transgenic

89 GCaMP6 calcium imaging approach that enables the effects of neurotransmitters on

90 adult ARN ${ }^{\text {KISS }}$ neurons to be assessed in the acute brain slice. To ensure that we

91 measure direct effects of these neuropeptides on kisspeptin neurons, intracellular

92 calcium concentrations ([Ca $\left.\left.{ }^{2+}\right] \mathrm{i}\right)$ were assessed in the presence of amino acid receptor

93 antagonists and tetrodotoxin (TTX).

\section{Materials and Methods}

96 Experimental animals

97 Mice were generated by crossing Kiss1-Cre ${ }^{+/}$(18) and homozygous floxed GCaMP6f 98 (Ai95(RCL-GCaMP6f)-D)(19) lines to generate mixed background 129S6Sv/Ev 99 C57BL6 Kiss1-Cre::GCaMP6f-lox-STOP-lox (Kiss1::GCaMP6) mice. Mice were group100 housed under conditions of controlled temperature $\left(22 \pm 2^{\circ} \mathrm{C}\right)$ and lighting (12-hour 101 light/12-hour dark cycle (lights on at 6:00h and off at 18:00h) with ad libitum access 102 to food and water. The University of Otago Animal Ethics Committee approved all 103 animal experimental protocols.

105 Immunohistochemistry

106 Four adult female Kiss1::GCaMP6f mice were ovariectomized under Halothane 107 anesthesia and 3-weeks later anesthetized and perfused through the heart with 4\% 108 paraformaldehyde, phosphate-buffered saline for free-floating dual 109 immunofluorescence histochemistry as reported previously $(20,21)$. Mice were 110 ovariectomized so as to increase the level of kisspeptin peptide in ARN neurons to 111 improve immunohistochemical detection. Primary antisera raised against GFP 112 (rabbit 1:5,000, Invitrogen; RRID:AB_221570) and kisspeptin (sheep 1:1,000, AC053 113 gift of Alain Caraty, Nouzilly, France)(22) were used to increase the GCaMP6 signal 114 and detect kisspeptin, respectively. Secondary antisera were biotinylated donkey 115 anti-sheep immunoglobulins (1:200, Jackson ImmunoResearch Labs, PA) followed by 116 streptavidin-568 (1:200, Molecular Probes), and donkey anti-rabbit-488 (1:200, 117 Jackson), respectively. Dual-fluorescence images were captured on a NikonA1+ 
118 inverted confocal microscope. Two sections at each of the rostral, middle and caudal

119 levels of the ARN were analyzed in each mouse by counting the total number of cells

120 that expressed GFP (GCaMP6) and/or kisspeptin.

121

122 Calcium imaging

123 The ${ }\left[\mathrm{Ca}^{2+}\right]$ of multiple ARN ${ }^{\mathrm{KISS}}$ neurons was monitored simultaneously in acute brain 124 slices using a methodology previously established for the preoptic kisspeptin 125 neurons (23). Coronal brain slices (250 $\mu$ m-thick) containing the rostral, middle and 126 caudal regions of the ARN were prepared from adult male and diestrous-stage female 127 Kiss1::GCaMP6f mice between 10:00-11:00h ( $\mathrm{N}=4$ for each sex, region and 128 neuropeptide) and constantly perfused (1mL/min) with $30^{\circ} \mathrm{C}, 95 \% \mathrm{O}_{2} / 5 \% \mathrm{CO}_{2}$ 129 equilibrated, artificial cerebrospinal fluid (aCSF) comprised of (mM) $\mathrm{NaCl} 120, \mathrm{KCl} 3$, $130 \mathrm{NaHCO}_{3} 26, \mathrm{NaH}_{2} \mathrm{PO} 41, \mathrm{CaCl}_{2} 2.5, \mathrm{MgCl}_{2} 1.2$ and glucose 10 . To ensure that only direct 131 neuropeptide responses were recorded from ARN ${ }^{\mathrm{KISS}}$ neurons, the aCSF contained 132 TTX $(0.5 \mu \mathrm{M})$ and the ionotropic $\mathrm{GABA}_{\mathrm{A}}$ and glutamate receptor antagonists 133 picrotoxin $(100 \mu \mathrm{M}), \mathrm{CNQX}(10 \mu \mathrm{M})$, and AP5 $(40 \mu \mathrm{M})$ at all times (all sourced from 134 Tocris Biosciences). Slices were placed under an upright Olympus BX51W1 135 microscope and multiple individual cells in a plane of focus visualized through a 40x 136 immersion objective using a xenon arc light source $(300 \mathrm{~W}$, filtered by a GFP filter 137 cube (excitation 470-490 nm, Chroma)) and a DG-4 shutter (Sutter Instruments) 138 providing $100 \mathrm{~ms}$ duration light at $2 \mathrm{~Hz}$. Epifluorescence $(495 \mathrm{~nm}$ long pass and 139 emission 500-520 nm) was collected using a Hamamatsu ORCA-ER digital CCD 140 camera.

141 The effects of neuropeptides on ARN ${ }^{\mathrm{KISS}}$ neuron GCaMP6f fluorescence were assessed 142 by measuring basal fluorescence over a 4 min period and then adding the test 143 neuropeptide to the aCSF for a two-min period before switching back to aCSF only. 144 Regions of interest over individual, non-overlapping, and in-focus fluorescent somata 145 were selected and analyzed using ImageJ software and custom R scripts. Individual 146 cells were considered to have responded if they exhibited an increase in fluorescence 147 during the 2-min test period that was greater than their mean baseline level +2 
148 standard deviations (SD) derived from basal recordings. To accommodate for the 149 gradual decline in fluorescence levels that occurs over the test period, the 150 fluorescence levels over the first 4-min basal period were divided into the first (b1) 151 and second (b2) two-minute basal recording periods and an adjusted baseline $(F)$ for 152 the 2-min stimulation period set at $=\mathrm{b} 2-(\mathrm{b} 1-\mathrm{b} 2)$. For visualizing data, values are 153 presented as relative fluorescence changes using $\frac{\Delta \mathrm{F}}{\mathrm{F}}=\frac{\mathrm{Ft}-\mathrm{F}}{\mathrm{F}} * 100$ where $F$ is the 154 adjusted baseline and $F_{t}$ is the fluorescence measured.

155 To assess effects of neuropeptides on ARN ${ }^{\mathrm{KISS}}$ neuron located at different rostro156 caudal levels of the ARN, four rostral, four middle and four caudal slices from four 157 separate mice were tested with each neuropeptide. The different rostrocaudal levels 158 were determined by the distinctive topography of kisspeptin neurons in each area 159 and the shape of the median eminence (Fig.1). Each slice received only one test. 160 Results are reported as number of cells examined (n) and numbers of slices or mice 161 (N). The effects of neurokinin B (NKB, 50nM), AVP (300nM) and VIP $(1 \mu \mathrm{M})$ (Tocris 162 Bioscience) were examined. Prior studies in the laboratory have shown that these 163 concentrations are effective in activating the firing of kisspeptin, GnRH and other 164 neurons in acute brain slices (23-25). Statistical analysis comparing between sexes 165 and ARN subregions was undertaken with two-way ANOVA and post-hoc Tukey tests.

\section{Results}

168 Expression of GCaMP6 in arcuate nucleus kisspeptin neurons

169 The distribution of GCaMP6-expressing cells throughout the rostro-caudal extent of 170 the ARN in Kiss1::GCaMP6f mice (Fig.1A) was identical to that reported for kisspeptin 171 neurons (21) with the largest numbers of cells detected in the caudal ARN (Table). 172 Dual-label immunofluorescence demonstrated that 88-95\% of GCaMP6 cells 173 expressed kisspeptin and virtually all (99\%) kisspeptin neurons contained GCaMP6 174 (Fig.1B-D, Table).

176 GCaMP6 calcium imaging 
177 The GCaMP6 imaging enabled the fluorescence levels of 8-25 ARN ${ }^{\text {KISS }}$ neurons to be 178 evaluated simultaneously in each brain slice. Initial control experiments in slices 179 from four diestrous female mice showed that 53 of the 54 recorded cells ( $\mathrm{N}=4$ slices) 180 exhibited a stable baseline level of fluorescence that gradually declined over time 181 (Fig.2). Only one of the 54 cells was found to show spontaneous fluctuations (Fig.2).

183 NKB activates all kisspeptin neurons in the ARN of males and females

184 To test the validity of this preparation, we first examined the effects of NKB as this 185 neuropeptide has been reported to have direct stimulatory effects on the firing of 186 nearly all ARN ${ }^{\text {KISS }}$ neurons in male mice $(24,26,27)$. Exposure to 50nM NKB was 187 found to evoke an increase in fluorescence levels in essentially all GCaMP6188 expressing cells located throughout the ARN (Fig.3A-C). Responses could be abrupt 189 or take over $1 \mathrm{~min}$ to occur with baseline levels typically restored to normal within 4$1905 \mathrm{~min}$ of the response (Fig.3C). In four diestrous Kiss1::GCaMP6f female mice, 37 191 rostral, 100 middle, and 65 caudal cells were tested in four brain slices from each 192 region with $100 \%$ of cells exhibiting a change in fluorescence signal that was > basal $193+2$ SD. The same result was found for male mice $(\mathrm{N}=4)$ with 28/28 rostral, 75/79 194 (95\%) middle and 84/87 (97\%) caudal cells responding to NKB (Fig.3D). Basal 195 fluorescence signals in males were the same as those observed for females with only 196 occasional evidence of spontaneous calcium transients. No significant differences 197 were detected between any regions or sexes ( $p>0.05$, Two-way ANOVA).

199 VIP activates caudal arcuate kisspeptin neurons in a sexually dimorphic manner.

200 The administration of $1 \mu \mathrm{M}$ VIP was found to have no effects upon GCaMP6 201 fluorescence in 35 kisspeptin neurons $(\mathrm{N}=4)$ located in the rostral-aspect of the ARN 202 in female Kiss1::GCaMP6f mice (Fig.4A). While the middle ARN (N=4) was similar 203 with only 2/58 (3\%) cells responding, 46/80 (58\%) kisspeptin neurons in the caudal 204 ARN (N=4) were activated by VIP (Fig.4A,B; p<0.05 compared with other subregions, 205 Two-way ANOVA, post-hoc Tukey's tests). These responses could take up to 2 min to 206 initiate and typically exhibited a fluctuating profile before returning to baseline up to 
10 min later (Fig.4B). Although a relationship between the basal level of fluorescence 208 and the magnitude of any response existed, responding cells could not be predicted 209 by their basal level of fluorescence. In male Kiss1::GCaMP6f mice, no cells in the 210 rostral $(n=32, N=4)$ or middle aspects of the ARN $(n=71, N=4)$ responded to VIP with 211 only $3 / 57(6 \%, N=4)$ kisspeptin neurons in the caudal stimulated ( $\mathrm{p}<0.05$ compared 212 to females, Two-way ANOVA, post-hoc Tukey's tests; Fig. 4C).

214 AVP activates caudal arcuate kisspeptin neurons in a sexually dimorphic manner.

215 Exposure to 300nM AVP had minimal effects on fluorescence levels in kisspeptin 216 neurons located in the rostral (2/34 cell responded, $6 \%, \mathrm{~N}=4)$ and middle ( $5 / 66$ cells, $2178 \%, \mathrm{~N}=4$ ) aspects of the ARN but increased intracellular calcium levels in 46 of 78 218 (59\%, N=4) cells located in the caudal ARN (Fig.5A; $p<0.05$ compared with other 219 subregions, Two-way ANOVA, post-hoc Tukey's tests). Responses evoked by AVP 220 were typically immediate upon entry of AVP into the bath but short-lived, sometimes 221 terminating during the application period (Fig.5B). In male Kiss1::GCaMP6f mice, 4$22212 \%$ of kisspeptin neurons responded throughout the rostro-caudal extent of the 223 ARN; $1 / 24$ rostral (4\%), 5/67 middle (8\%) and 10/81 caudal (12\%)( $\mathrm{N}=4$ each, 224 Fig.5C). The numbers of kisspeptin neurons responding to AVP were significantly 225 different in the caudal ARN of females compared to other subregions and males 226 ( $\mathrm{p}<0.05$ compared to females, Two-way ANOVA, post-hoc Tukey's tests; Fig. 5C).

\section{Discussion}

231 We report here the unexpected observation that kisspeptin neurons located at 232 different rostro-caudal locations within the ARN can express different functional 233 neuropeptide receptors and, further, that this is sexually dimorphic. Whereas all 234 ARN ${ }^{\mathrm{KISS}}$ neurons in both males and females express tachykinin receptors activated by $235 \mathrm{NKB}$, the kisspeptin neurons activated by AVP and VIP are located primarily within 236 the caudal ARN and exhibit a marked female-dominant sex difference. These 237 observations highlight the functional heterogeneity and striking sexually dimorphic 
238 nature of the $\mathrm{ARN}^{\mathrm{KISS}}$ neuron population and, further, indicate that this may be 239 organized in a rostro-caudal topographic manner.

241 The Kiss1::GCaMP6f mouse line was found to provide high fidelity targeting of 242 GCaMP6 to the ARN ${ }^{\text {KISS }}$ neuron population with essentially $100 \%$ of kisspeptin 243 neurons expressing GCAMP6 and these cells representing 88-95\% of all GCaMP6 244 neurons located in the ARN. As such, this mouse line provides a good model 245 preparation for examining the direct responses of ex-vivo $\mathrm{ARN}^{\mathrm{KISS}}$ neurons to putative 246 neurotransmitters and neuropepitdes. Nevertheless, the approach has caveats, 247 principally being that inhibitory effects of transmitters, or receptor activation that 248 does not directly or indirectly modulate $\mathrm{i}\left[\mathrm{Ca}^{2+}\right]$, will not be revealed. Thus, false 249 negatives may occur but positive responses will be indicative of the presence of 250 cognate receptors for the transmitter examined.

252 Prior electrophysiological brain slice studies have shown that 90-100\% of ARN ${ }^{\mathrm{KISS}}$ 253 neurons are activated by NKB or tachykinin receptor agonists in male mice $(24,26$, 254 27). In good agreement, we find that essentially $100 \%$ of $A_{R N}{ }^{K I S S}$ neurons in intact 255 male mice respond directly to $\mathrm{NKB}$ with elevated $\mathrm{i}\left[\mathrm{Ca}^{2+}\right]$ and now extend this to 256 demonstrate that this is also the case in diestrous female mice. Prior studies using 257 dual-label in situ hybridization have reported that $75-100 \%$ of ARN ${ }^{\mathrm{KISS}}$ neurons 258 located in the middle aspects of the ARN express Tacr3 transcripts in female mice (27, 259 28). By targeting recordings to the rostral, middle and caudal aspects of the ARN we 260 are able to demonstrate remarkable consistency in the functional expression of NKB261 activated receptors by ARN KISS neurons in both males and females. As a sub262 population of ARN ${ }^{\mathrm{KISS}}$ neurons will be the GnRH pulse generator, these observations 263 are in good agreement with in vivo data showing that intracerebroventricular 264 administration of senktide, an NK3R agonist, activates LH secretion in both intact 265 male and diestrous-stage female mice (29).

266

267 In striking contrast to the effects of NKB, both AVP and VIP exerted subregion- and 268 sex-dependent effects on ARN ${ }^{\mathrm{KISS}}$ neuron $\mathrm{i}\left[\mathrm{Ca}^{2+}\right]$. Whereas $58 \%$ of caudal ARN ${ }^{\mathrm{KISS}}$ 
neurons responded to VIP in females only $6 \%$ were activated in male, and essentially

270 no cells were stimulated in the rostral or middle regions of the ARN in either sex.

271 Similarly, 58\% of caudal ARN ${ }^{\mathrm{KISS}}$ neurons were activated by AVP compared with only

$2724-12 \%$ of neurons in other regions or in males. This indicates that female caudal

273 ARN ${ }^{\text {KISS }}$ neurons preferentially express functional receptors for VIP and AVP.

274 Although not addressed in this study, it is possible that changes in ARN ${ }^{\text {KISS }}$ neuron

275 sensitivity to AVP and VIP may occur with postnatal development or across the

276 estrous cycle in females.

277

278 Similar numbers of caudal ARN ${ }^{\mathrm{KISS}}$ neurons are activated by AVP and VIP in female 279 but they evoke very different profiles of changing $\mathrm{i}\left[\mathrm{Ca}^{2+}\right]$. The molecular identities of 280 the receptors activated are not known although VIP at $1 \mu \mathrm{M}$ concentrations would be 281 expected to activate both type 1 (VPAC1) and type 2 (VPAC2) VIP receptors in 282 addition to the pituitary adenylate cyclase-activating peptide (PACAP) receptor (30).

283 Recent studies have shown that PACAP neurons located in the premammillary 284 nucleus project to ARN ${ }^{\mathrm{KISS}}$ neurons and can directly activate a sub-population of 285 caudal ARN neurons in female mice (31). Hence, it is possible that PACAP is the 286 endogenous ligand for VIP receptors expressed by ARN ${ }^{\mathrm{KISS}}$ neurons. Recent 287 transcriptome-based cell sorting strategies failed to identify any AVP or VIP/PACAP 288 receptor transcripts in pools of ARN ${ }^{\mathrm{KISS}}$ neurons from young female or mixed 289 male/female mice $(32,33)$. Given the sex-dependent and highly regionalised nature 290 of AVP and VIP receptor expression revealed here, future transcriptomic studies of 291 ARN ${ }^{\text {KISS }}$ neuron will need to take potential subregion and sex differences into 292 consideration.

293

294 The sex- and region-specific nature of AVP and VIP effects identified here would not 295 support the concept of a generalized direct circadian regulation of ARN ${ }^{\mathrm{KISS}}$ neurons 296 by these neuropeptides. Studies have found day-night differences in LH pulse 297 frequency in both human males and females (10-12) although their dependence on 298 circadian cues, as opposed to environmental influences such as sleep and stress, has 
been challenged (34). Further, while studies in rodents have identified circadian-like changes in LH secretion in peripubertal females, it has remained unclear whether this was related to pulse or surge modes of LH secretion (35). Hence, it is possible that there is no direct or substantial circadian modulation of the different ARN ${ }^{\text {KISS }}$ neuron sub-populations. Instead, VIP/PACAP and AVP inputs to ARN ${ }^{\mathrm{KISS}}$ neurons may 304 originate from neural populations located outside the suprachiasmatic nucleus, as 305 has recently been demonstrated for PACAP neurons of the premammilary nucleus 306

The function of neuropeptidergic inputs directed at caudal ARN ${ }^{\mathrm{KISS}}$ neurons in the

311 female can only be speculated upon at present. Sex differences in ARN ${ }^{K I S S}$ morphology

312 and function have been documented $(20,36)$ but the extent to which this depends on 313 sexually differentiated inputs is unknown. Further, the functions of AVP/VIP314 sensitive ARN ${ }^{\text {KISS }}$ neurons are unknown and may even be unrelated to the regulation 315 of GnRH neurons. Indeed, tract tracing studies have shown that caudal ARNKISS 316 neurons project to multiple limbic brain region in the mouse (37). On the other hand, 317 recent optogenetic studies have indicated that the $\mathrm{ARN}^{\mathrm{KISS}}$ neuron pulse generator 318 may be located in the middle-caudal aspects of the nucleus (21) although no further 319 features or markers of this population have been identified as yet. One intriguing 320 speculation is that SCN inputs to ARN ${ }^{\text {KISS }}$ neurons may modulate the LH surge. 321 Although there is little evidence for the ARN to be involved in the timing of the LH 322 surge (38), recent studies have suggested that the ARN KISS neurons may be involved 323 in regulating the amplitude of the LH surge $(39,40)$, potentially through direct 324 projections to preoptic area kisspeptin neurons (41).

326 In summary, these studies reveal marked sex- and subregion-specific effects of two 327 neuropeptides on ARN ${ }^{\mathrm{KISS}}$ neurons. These observations reinforce the concept of 328 functional heterogeneity amongst the ARN ${ }^{\text {KISS }}$ neuron population. Alongside other 329 evidence $(21,37)$, it seems that this heterogeneity may, in part, be organized on a 
330 rostro-caudal basis within the ARN of the mouse. In contrast, we find that the 331 response of ARN ${ }^{\mathrm{KISS}}$ neurons to NKB is extremely uniform impacting upon essentially 332 all kisspeptin neurons throughout the nucleus in both males and females. The 333 functional relevance of this heterogeneity with respect to pulse generation as well as 334 other functions of the ARN KISS neuron population awaits elucidation. More 335 specifically, the surprising observation of sexually dimorphic and region-specific AVP 336 and VIP signaling within the $\mathrm{ARN}^{\mathrm{KISS}}$ neuron population raises intriguing questions as 337 to the roles of these neuropeptides within the ARN.

\section{Acknowledgements}

342 This work was supported by University of Otago Health Science Division Masters 343 Scholarship (DS) and the New Zealand Health Research Council. Author 344 Contributions: DS designed and performed calcium imaging studies, GK performed 345 immunohistochemistry studies, WH provided essential reagents, RP designed 346 research and analysed data, AH designed research, analysed data and co-wrote the 347 manuscript alongside the other authors. 


\section{References}

349

350

351

352

353

354

355

356

357

358

359

360

361

362

363

364

365

366

367

368

369

370

371

372

373

374

375

376

377

378

379

380

381

382

383

384

385

386

387

388

389

390

1. Herbison AE. The gonadotropin-releasing hormone pulse generator. Endocrinology. 2018: Endocrinology, en.2018-00653.

2. Jayasena CN, Franks S. The management of patients with polycystic ovary syndrome. Nature reviews Endocrinology. 2014; 10: 624-636.

3. Burt Solorzano CM, Beller JP, Abshire MY, Collins JS, McCartney CR, Marshall JC. Neuroendocrine dysfunction in polycystic ovary syndrome. Steroids. 2012; 77: 332337.

4. Fourman LT, Fazeli PK. Neuroendocrine causes of amenorrhea--an update. J Clin Endocrinol Metab. 2015; 100: 812-824.

5. Goodman RL, Okhura S, Okamura H, Coolen LM, Lehman MN. KNDy hypothesis for generation of GnRH pulses; evidence from sheep and goats. In: Herbison AE, Plant TM, eds. The GnRH neuron and its control. Hoboken, NJ, USA: John Wiley and Sons Ltd 2018: 289-324.

6. Herbison AE. Control of puberty onset and fertility by gonadotropin-releasing hormone neurons. Nature reviews Endocrinology. 2016; 12: 452-466.

7. Yeo SH, Colledge WH. The Role of Kiss1 Neurons As Integrators of Endocrine, Metabolic, and Environmental Factors in the Hypothalamic-Pituitary-Gonadal Axis. Frontiers in endocrinology. 2018; 9: 188.

8. Kriegsfeld LJ. Circadian regulation of kisspeptin in female reproductive functioning. Adv Exp Med Biol. 2013; 784: 385-410.

9. Simonneaux V, Bahougne T. A Multi-Oscillatory Circadian System Times Female Reproduction. Frontiers in endocrinology. 2015; 6: 157.

10. Spratt DI, O'Dea LS, Schoenfeld D, Butler J, Rao PN, Crowley WF, Jr. Neuroendocrine-gonadal axis in men: frequent sampling of LH, FSH, and testosterone. Am J Physiol. 1988; 254: E658-666.

11. Boyar R, Finkelstein J, Roffwarg H, Kapen S, Weitzman E, Hellman L. Synchronization of augmented luteinizing hormone secretion with sleep during puberty. N Engl J Med. 1972; 287: 582-586.

12. Collins JS, Beller JP, Burt Solorzano C, Patrie JT, Chang RJ, Marshall JC, McCartney CR. Blunted day-night changes in luteinizing hormone pulse frequency in girls with obesity: the potential role of hyperandrogenemia. J Clin Endocrinol Metab. 2014; 99: 2887-2896.

13. Lukas M, Bredewold R, Neumann ID, Veenema AH. Maternal separation interferes with developmental changes in brain vasopressin and oxytocin receptor binding in male rats. Neuropharmacology. 2010; 58: 78-87.

14. Mounien L, Bizet P, Boutelet I, Gourcerol G, Fournier A, Vaudry H, Jegou S. Pituitary adenylate cyclase-activating polypeptide directly modulates the activity of proopiomelanocortin neurons in the rat arcuate nucleus. Neuroscience. 2006; 143: 155-163.

15. Ronnekleiv OK, Fang Y, Zhang C, Nestor CC, Mao P, Kelly MJ. Research resource: Gene profiling of $\mathrm{G}$ protein-coupled receptors in the arcuate nucleus of the female. Mol Endocrinol. 2014; 28: 1362-1380. 
16. Yi CX, van der Vliet J, Dai J, Yin G, Ru L, Buijs RM. Ventromedial arcuate nucleus communicates peripheral metabolic information to the suprachiasmatic nucleus. Endocrinology. 2006; 147: 283-294.

17. Guzman-Ruiz M, Saderi N, Cazarez-Marquez F, Guerrero-Vargas NN, Basualdo MC, Acosta-Galvan G, Buijs RM. The suprachiasmatic nucleus changes the daily activity of the arcuate nucleus alpha-MSH neurons in male rats. Endocrinology. 2014; 155: 525-535.

18. Yeo SH, Kyle V, Morris PG, Jackman S, Sinnett-Smith LC, Schacker M, Chen C, Colledge WH. Visualisation of Kiss1 neurone distribution using a Kiss1-CRE transgenic mouse. J Neuroendocrinol. 2016; 28.

19. Madisen L, Garner AR, Shimaoka D, Chuong AS, Klapoetke NC, Li L, van der Bourg A, Niino Y, Egolf L, Monetti C, Gu H, Mills M, Cheng A, Tasic B, Nguyen TN, Sunkin SM, Benucci A, Nagy A, Miyawaki A, Helmchen F, Empson RM, Knopfel T, Boyden ES, Reid RC, Carandini M, Zeng H. Transgenic mice for intersectional targeting of neural sensors and effectors with high specificity and performance. Neuron. 2015; 85: 942-958.

20. Han SY, McLennan T, Czieselsky K, Herbison AE. Selective optogenetic activation of arcuate kisspeptin neurons generates pulsatile luteinizing hormone secretion. Proc Natl Acad Sci U S A. 2015; 112: 13109-13114.

21. Clarkson J, Han SY, Piet R, McLennan T, Kane GM, Ng J, Porteous RW, Kim JS, Colledge WH, Iremonger KJ, Herbison AE. Definition of the hypothalamic GnRH pulse generator in mice. Proc Natl Acad Sci U S A. 2017; 114: E10216-E10223.

22. Franceschini I, Yeo SH, Beltramo M, Desroziers E, Okamura H, Herbison AE, Caraty A. Immunohistochemical evidence for the presence of various kisspeptin isoforms in the Mammalian brain. J Neuroendocrinol. 2013; 25: 839-851.

23. Piet R, Fraissenon A, Boehm U, Herbison AE. Estrogen permits vasopressin signaling in preoptic kisspeptin neurons in the female mouse. J Neurosci. 2015; 35: 6881-6892.

24. de Croft S, Boehm U, Herbison AE. Neurokinin B activates arcuate kisspeptin neurons through multiple tachykinin receptors in the male mouse. Endocrinology. 2013; 154: 2750-2760.

25. Piet R, Dunckley H, Lee K, Herbison AE. Vasoactive intestinal peptide excites GnRH neurons in male and female mice. Endocrinology. 2016: en20161399.

26. Ruka KA, Burger LL, Moenter SM. Regulation of arcuate neurons coexpressing kisspeptin, neurokinin $\mathrm{B}$, and dynorphin by modulators of neurokinin 3 and kappaopioid receptors in adult male mice. Endocrinology. 2013; 154: 2761-2771.

27. Navarro VM, Gottsch ML, Wu M, Garcia-Galiano D, Hobbs SJ, Bosch MA, Pinilla L, Clifton DK, Dearth A, Ronnekleiv OK, Braun RE, Palmiter RD, Tena-Sempere M, Alreja M, Steiner RA. Regulation of NKB pathways and their roles in the control of Kiss1 neurons in the arcuate nucleus of the male mouse. Endocrinology. 2011; 152: $4265-4275$.

28. Navarro VM, Gottsch ML, Chavkin C, Okamura H, Clifton DK, Steiner RA. Regulation of gonadotropin-releasing hormone secretion by kisspeptin/dynorphin/neurokinin B neurons in the arcuate nucleus of the mouse. $\mathrm{J}$ Neurosci. 2009; 29: 11859-11866.

29. Navarro VM, Bosch MA, Leon S, Simavli S, True C, Pinilla L, Carroll RS, Seminara SB, Tena-Sempere M, Ronnekleiv OK, Kaiser UB. The integrated hypothalamic 
tachykinin-kisspeptin system as a central coordinator for reproduction. Endocrinology. 2015; 156: 627-637.

30. Harmar AJ, Fahrenkrug J, Gozes I, Laburthe M, May V, Pisegna JR, Vaudry D, Vaudry H, Waschek JA, Said SI. Pharmacology and functions of receptors for vasoactive intestinal peptide and pituitary adenylate cyclase-activating polypeptide: IUPHAR review 1. Br J Pharmacol. 2012; 166: 4-17.

31. Ross RA, Leon S, Madara JC, Schafer D, Fergani C, Maguire CA, Verstegen AM, Brengle E, Kong D, Herbison AE, Kaiser UB, Lowell BB, Navarro VM. PACAP neurons in the ventral premammillary nucleus regulate reproductive function in the female mouse. eLife. 2018; 7.

32. Chen R, Wu X, Jiang L, Zhang Y. Single-Cell RNA-Seq Reveals Hypothalamic Cell Diversity. Cell reports. 2017; 18: 3227-3241.

33. Campbell JN, Macosko EZ, Fenselau H, Pers TH, Lyubetskaya A, Tenen D, Goldman M, Verstegen AM, Resch JM, McCarroll SA, Rosen ED, Lowell BB, Tsai LT. A molecular census of arcuate hypothalamus and median eminence cell types. Nat Neurosci. 2017; 20: 484-496.

34. Klingman KM, Marsh EE, Klerman EB, Anderson EJ, Hall JE. Absence of circadian rhythms of gonadotropin secretion in women. J Clin Endocrinol Metab. 2011; 96: 1456-1461.

35. Urbanski HF, Ojeda SR. The juvenile-peripubertal transition period in the female rat: establishment of a diurnal pattern of pulsatile luteinizing hormone secretion. Endocrinology. 1985; 117: 644-649.

36. Desroziers E, Mikkelsen JD, Duittoz A, Franceschini I. Kisspeptin-immunoreactivity changes in a sex- and hypothalamic-region-specific manner across rat postnatal development. J Neuroendocrinol. 2012; 24: 1154-1165.

37. Yeo SH, Herbison AE. Projections of arcuate nucleus and rostral periventricular kisspeptin neurons in the adult female mouse brain. Endocrinology. 2011; 152: 23872399.

38. Herbison AE. Physiology of the adult GnRH neuronal network. In: Plant TM, Zeleznik AJ, eds. Knobil and Neill's Physiology of Reproduction. 4th ed: Academic Press 2015: 399-467.

39. Mittelman-Smith MA, Krajewski-Hall SJ, McMullen NT, Rance NE. Ablation of KNDy Neurons Results in Hypogonadotropic Hypogonadism and Amplifies the Steroid-Induced LH Surge in Female Rats. Endocrinology. 2016; 157: 2015-2027.

40. Helena CV, Toporikova N, Kalil B, Stathopoulos AM, Pogrebna VV, Carolino RO, Anselmo-Franci JA, Bertram R. KNDy Neurons Modulate the Magnitude of the Steroid-Induced Luteinizing Hormone Surges in Ovariectomized Rats. Endocrinology. 2015; 156: 4200-4213.

41. Qiu J, Nestor CC, Zhang C, Padilla SL, Palmiter RD, Kelly MJ, Ronnekleiv OK. Highfrequency stimulation-induced peptide release synchronizes arcuate kisspeptin neurons and excites GnRH neurons. eLife. 2016; 5: e16246. 


\section{Figure legends}

481 Figure 1. Distribution of GCaMP6 in arcuate nucleus (ARN). A. Images from the same 482 adult female mouse showing the GFP-immunofluorescence (GCaMP6) in the rostral, 483 middle and caudal levels of the ARN. B-D, confocal images showing dual fluorescence 484 for GFP- (B) and kisspeptin- (C) immunofluorescence, and with the overlapping 485 signals represented in D.

487 Figure 2. Baseline GCaMP6 fluorescence levels in arcuate kisspeptin neurons. A. Raw 488 fluorescence levels of eight ARN kisspeptin neurons located in a middle arcuate 489 nucleus brain slice over $12 \mathrm{~min}$. B. Higher resolution change in fluorescence levels of 4905 of these cells showing the one cell (cell 3) that exhibited spontaneous fluctuations.

492 Figure 3. NKB activates essentially all kisspeptin neurons in both male and female mice. 493 A. Single frame photograph of GCaMP6 fluorescence in the middle ARN of a slice being 494 imaged. The five cells shown in C are labelled. B. Raw fluorescence recordings from 49521 kisspeptin neurons in that brain slice showing their response to a 2-min 496 application of 50nM NKB (grey bar) in the presence of TTX and amino acid receptor 497 antagonists. C. Higher resolution change in fluorescence levels from the five cells 498 depicted in A. Colors are the same as in B. D. Histogram showing the percentage of 499 kisspeptin neurons in the rostral, middle and caudal aspects of the ARN that 500 responded to NKB in male and female mice $(\mathrm{N}=4$, each).

502 Figure 4. VIP preferentially activates caudal ARN kisspeptin neurons in female mice. A. 503 Raw fluorescence traces from the rostral, middle and caudal aspects of the ARN from 504 the same diestrous female Kiss1::GCaMP6f mouse. The two-min $1 \mu \mathrm{M}$ VIP exposure 505 period is indicated by the grey bar and each colored line represents a different cell. $\mathbf{B}$. 506 Higher resolution changes in fluorescence showing the response profiles of six caudal 507 kisspeptin neurons to VIP. C. Histogram showing the percentage of kisspeptin 508 neurons in the rostral, middle and caudal aspects of the ARN responding to VIP in 
509 male and female mice $\left(\mathrm{N}=4\right.$ each) ${ }^{*} \mathrm{p}<0.05$ compared to all other groups, Two-way 510 ANOVA with post-hoc Tukey tests.

512 Figure 5. AVP preferentially activates caudal ARN kisspeptin neurons in female mice. 513 A. Raw fluorescence traces from the rostral, middle and caudal aspects of the ARN 514 from diestrous female Kiss1::GCaMP6f mouse. The two-min 300nM AVP exposure 515 period is indicated by the grey bar and each colored line represents a different cell. 516 Note the orange cell in the caudal traces that was discarded from analysis as it 517 exhibited a spontaneous fluctuation in fluorescence prior to the test with AVP. B. 518 Higher resolution change in fluorescence images showing the AVP response profiles 519 of five of the caudal kisspeptin neurons shown in A. C. Histogram showing the 520 percentage of kisspeptin neurons in the rostral, middle and caudal aspects of the ARN 521 responding to AVP in male and female mice ( $\mathrm{N}=4$ each). ${ }^{*} \mathrm{p}<0.05$ compared to all 522 other groups, Two-way ANOVA with post-hoc Tukey tests. 
524 Table

\begin{tabular}{|l|c|c|c|}
\hline & $\begin{array}{l}\text { nos. Kiss neurons } \\
\text { / hemi-section }\end{array}$ & $\begin{array}{l}\text { \% GCaMP6 cells } \\
\text { +ve for kisspeptin }\end{array}$ & $\begin{array}{l}\text { \% kisspeptin cells } \\
\text { +ve for GCaMP6 }\end{array}$ \\
\hline rostral ARN & $37 \pm 14$ & $88 \pm 7 \%$ & $99 \pm 1 \%$ \\
\hline middle ARN & $60 \pm 7$ & $94 \pm 1 \%$ & $99 \pm 1 \%$ \\
\hline caudal ARN & $68 \pm 8$ & $95 \pm 2 \%$ & $99 \pm 1 \%$ \\
\hline
\end{tabular}

525

526 Table showing the numbers of kisspeptin-immunoreactive neurons detected in the

527 three subregions of the ARN and their levels of co-expression with GCaMP6. N $=4$ 528 ovariectomized female mice. 

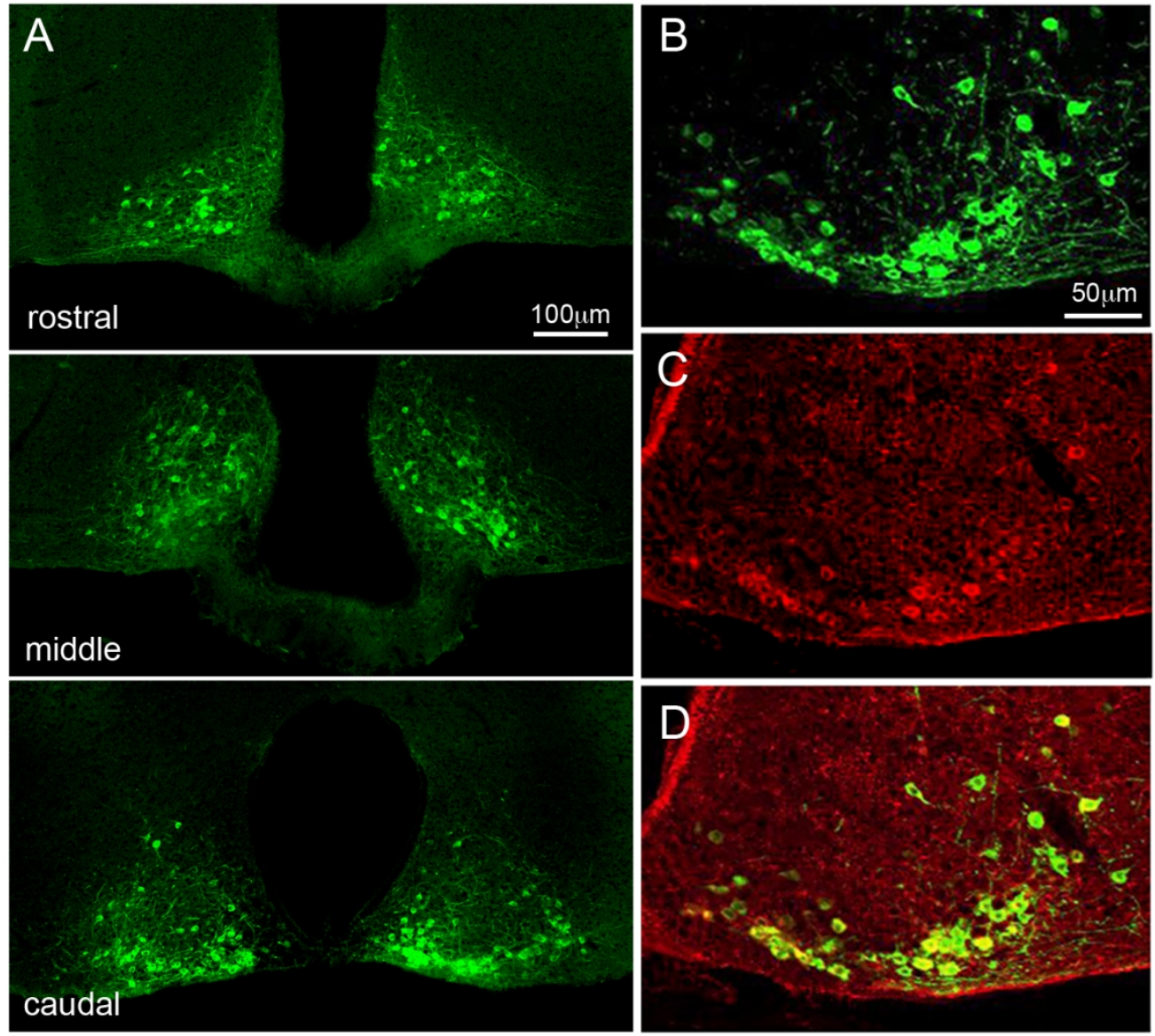

Figure 1.

Figure 1. Distribution of GCaMP6 in arcuate nucleus (ARN). A. Images from the same adult female mouse showing the GFP-immunofluorescence (GCaMP6) in the rostral, middle and caudal levels of the ARN. B-D, confocal images showing dual fluorescence for GFP- (B) and kisspeptin- (C) immunofluorescence, and with the overlapping signals represented in $\mathrm{D}$. 

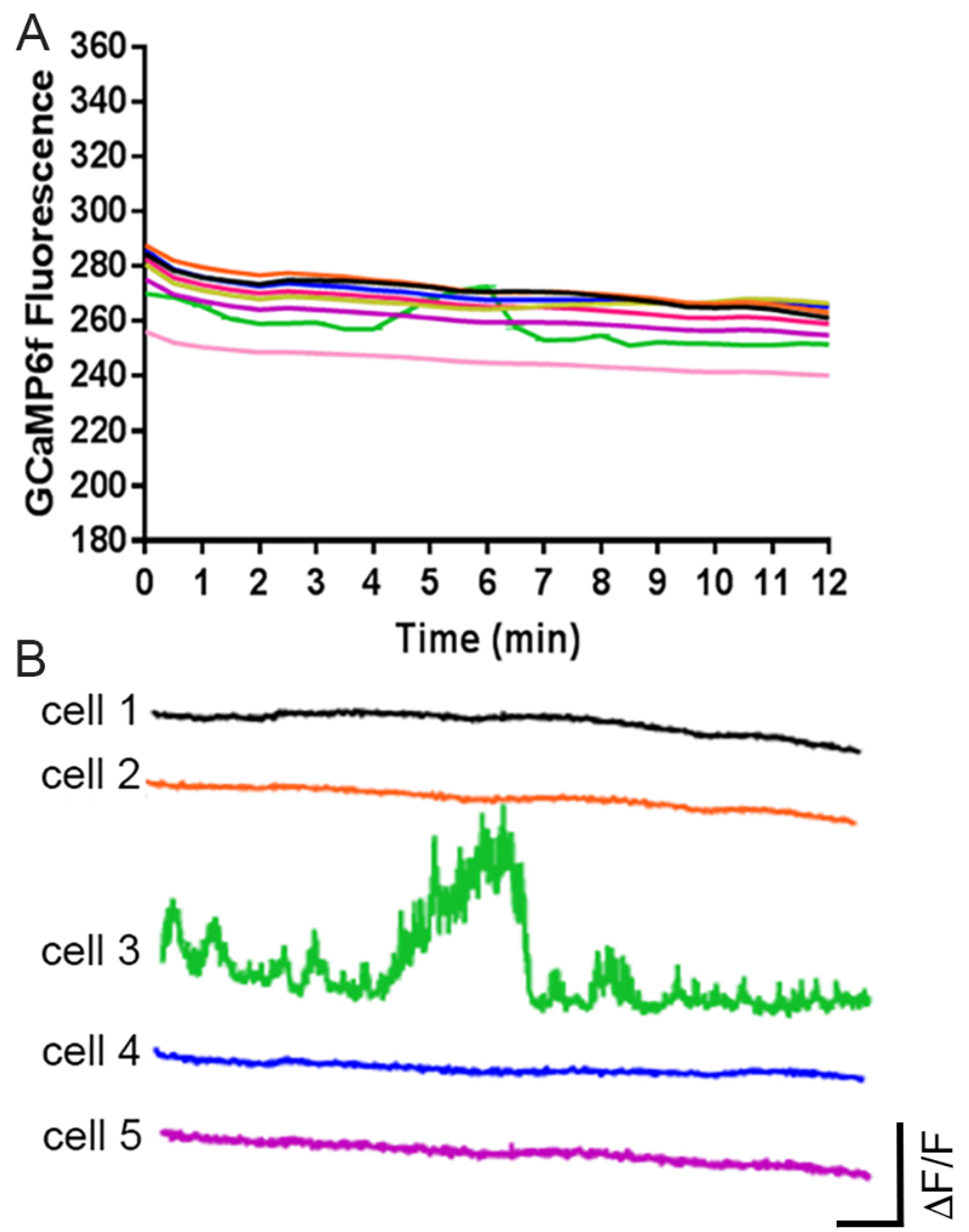

$1 \mathrm{~min}$

Figure 2

Figure 2. Baseline GCaMP6 fluorescence levels in arcuate kisspeptin neurons. A. Raw fluorescence levels of eight ARN kisspeptin neurons located in a middle arcuate nucleus brain slice over 12 min. B. Higher resolution change in fluorescence levels of 5 of these cells showing the one cell (cell 3 ) that exhibited spontaneous fluctuations.

$76 \times 110 \mathrm{~mm}(300 \times 300 \mathrm{DPI})$ 
2

3

4

5

6

7

8
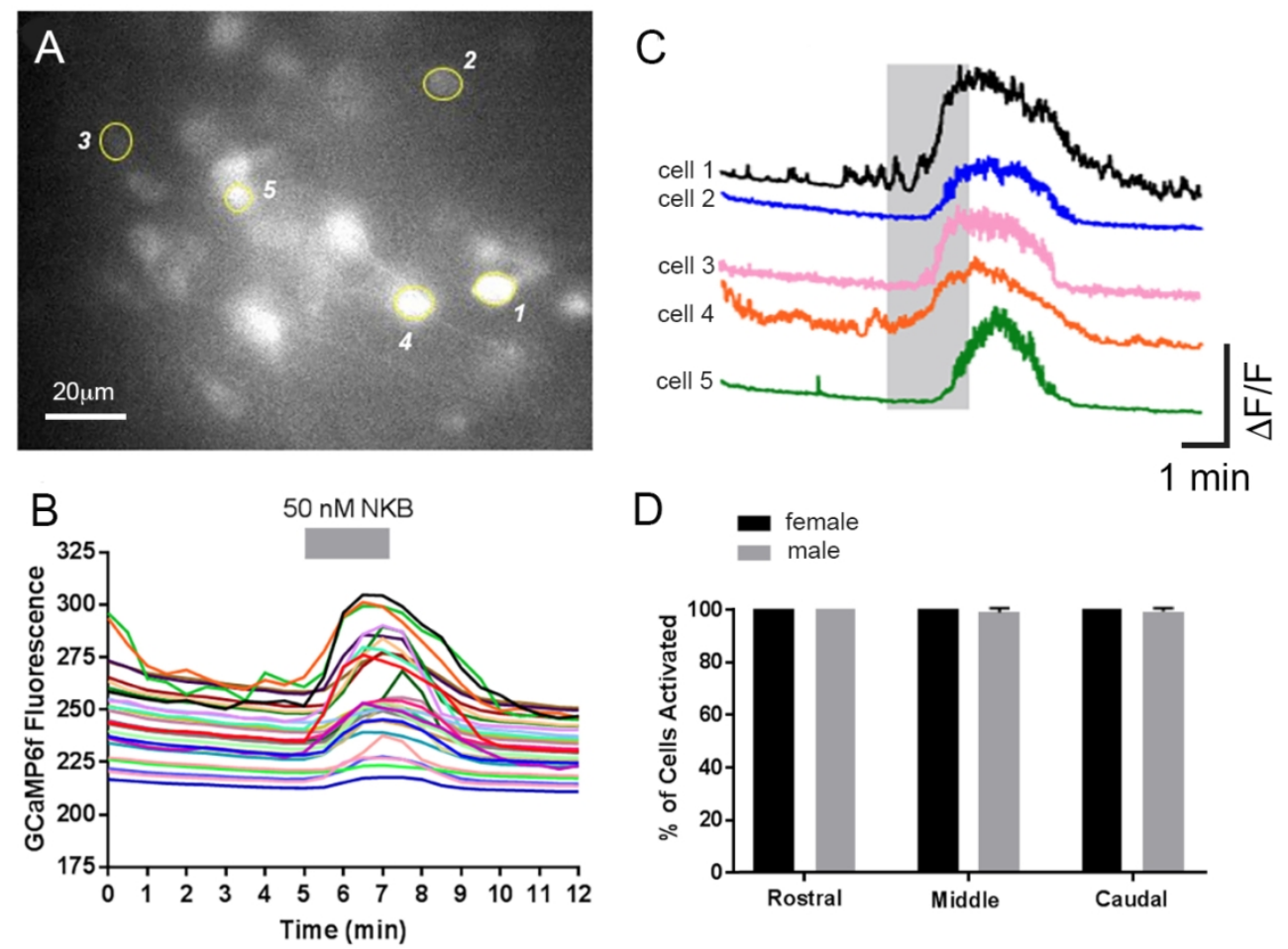

Figure 3

Figure 3. NKB activates essentially all kisspeptin neurons in both male and female mice. A. Single frame photograph of GCaMP6 fluorescence in the middle ARN of a slice being imaged. The five cells shown in $C$ are

labelled. B. Raw fluorescence recordings from 21 kisspeptin neurons in that brain slice showing their response to a 2-min application of 50nM NKB (grey bar) in the presence of TTX and amino acid receptor antagonists. C. Higher resolution change in fluorescence levels from the five cells depicted in A. Colors are the same as in B. D. Histogram showing the percentage of kisspeptin neurons in the rostral, middle and caudal aspects of the ARN that responded to NKB in male and female mice $(\mathrm{N}=4$, each). 

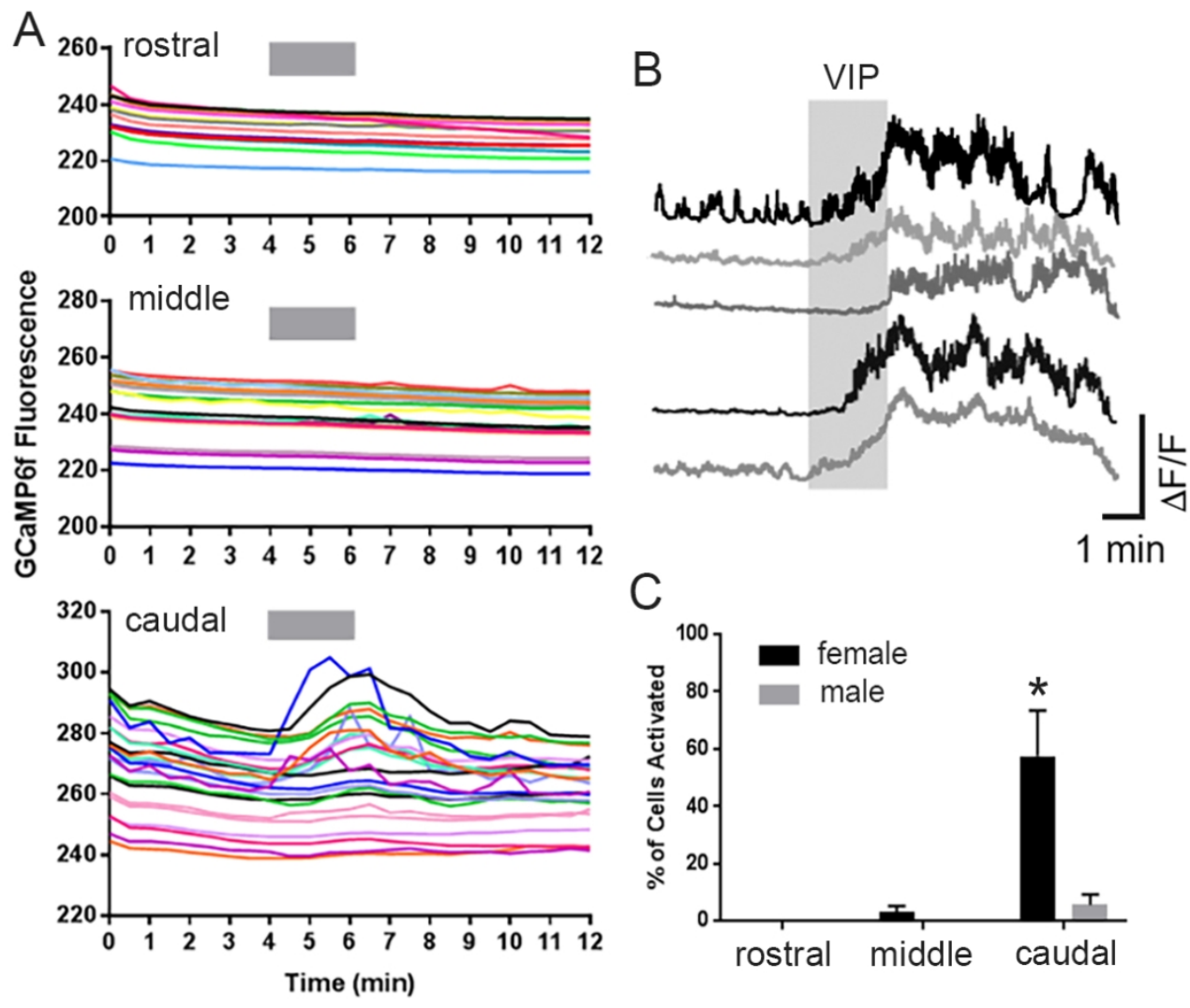

Figure 4

Figure 4. VIP preferentially activates caudal ARN kisspeptin neurons in female mice. A. Raw fluorescence traces from the rostral, middle and caudal aspects of the ARN from the same diestrous female

Kiss1::GCaMP6f mouse. The two-min 1 $\square$ M VIP exposure period is indicated by the grey bar and each colored line represents a different cell. B. Higher resolution changes in fluorescence showing the response profiles of six caudal kisspeptin neurons to VIP. C. Histogram showing the percentage of kisspeptin neurons in the rostral, middle and caudal aspects of the ARN responding to VIP in male and female mice ( $\mathrm{N}=4$ each) $* \mathrm{p}<0.05$ compared to all other groups, Two-way ANOVA with post-hoc Tukey tests. 

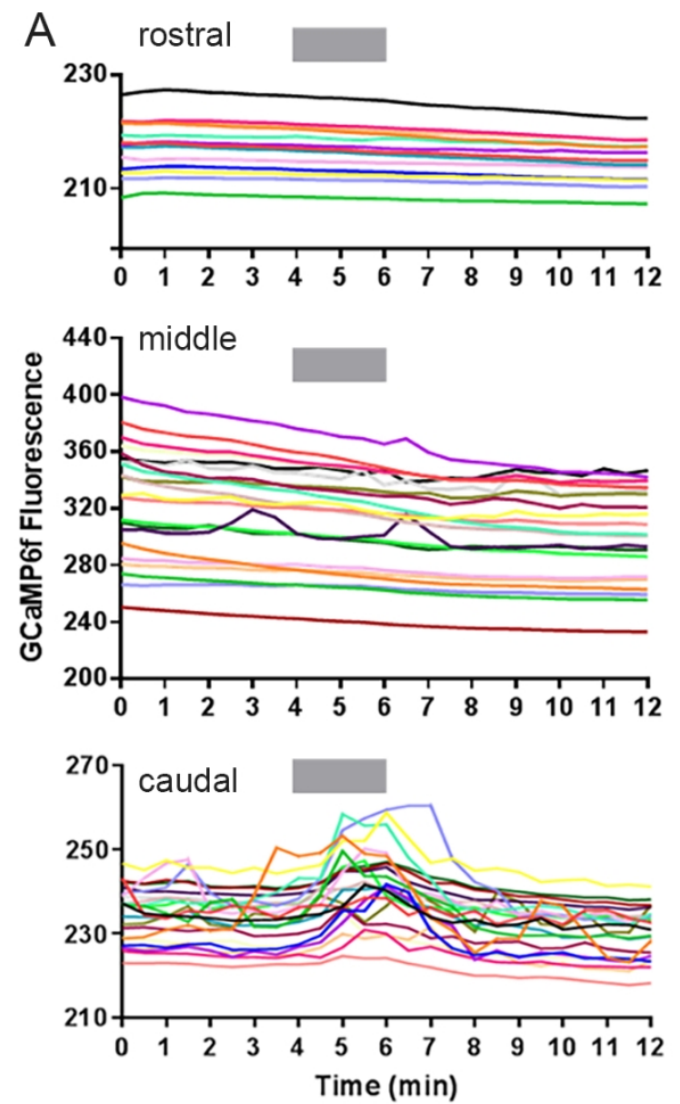

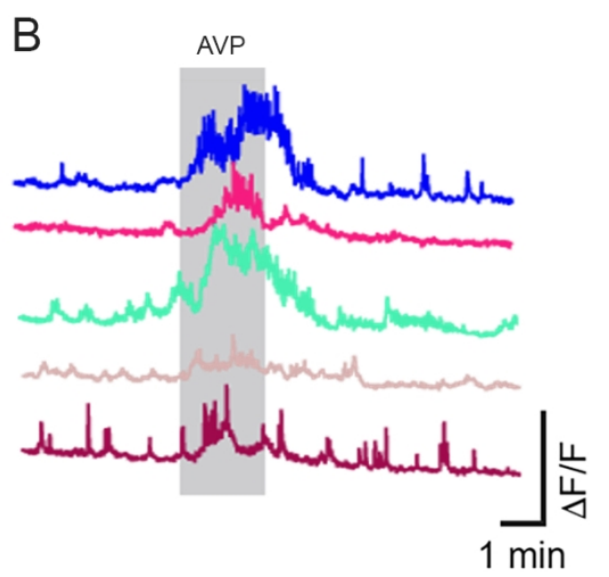

C

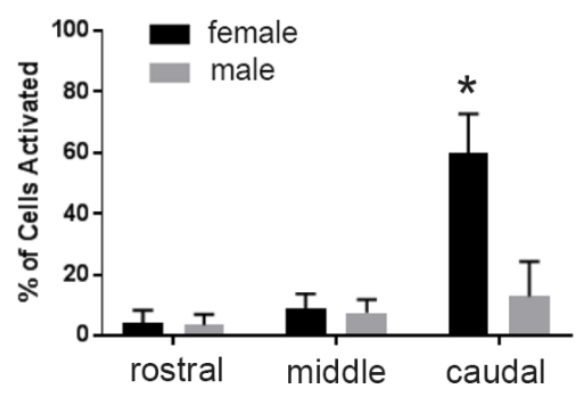

Figure 5

Figure 5. AVP preferentially activates caudal ARN kisspeptin neurons in female mice. A. Raw fluorescence traces from the rostral, middle and caudal aspects of the ARN from diestrous female Kiss1::GCaMP6f mouse. The two-min 300nM AVP exposure period is indicated by the grey bar and each colored line represents a different cell. Note the orange cell in the caudal traces that was discarded from analysis as it exhibited a spontaneous fluctuation in fluorescence prior to the test with AVP. B. Higher resolution change in fluorescence images showing the AVP response profiles of five of the caudal kisspeptin neurons shown in A. C. Histogram showing the percentage of kisspeptin neurons in the rostral, middle and caudal aspects of the ARN responding to AVP in male and female mice ( $N=4$ each). $* p<0.05$ compared to all other groups, Twoway ANOVA with post-hoc Tukey tests. 